\title{
Research on Reward and Punishment System of Soldiers in Jinzhou Regiment District
}

\author{
Wenhui Wang ${ }^{a}$, Xin Wen \\ School of Politics and History, Bohai University, Jinzhou, 121013, China \\ a2605245575@qq.com, b174279749@qq.com
}

Keywords: Jinzhou regiment district; soldiers; reward system; punishment system

\begin{abstract}
Reward and punishment system of soldiers is a mean of managing soldiers in the military, and their ultimate goal is to motivate soldiers to ensure combat and discipline. After the study, in the period of Chinese civil war, Jinzhou regiment district has more stringent management to the reward and punishment system of soldiers. Therefore, this military has been in stable, united state, establish the foundation for the Communist Party successfully took over Jinzhou. Through the study of Jinzhou regiment district and its superior management area between the documents and found Jinzhou regiment in the form of incentives are mainly promoted, recorded meritorious service, the order of the award, and the main form of punishment including the dismissal, recording, notification, punishment and so on. This kind of reward and punishment in the army management has played an important role, making the soldiers fulfill their duties, and dare not break the law. This paper makes further comments and research on the specific measures and significance of the reward and punishment of soldiers in Jinzhou regiment.
\end{abstract}

\section{Introduction}

Jinzhou regiment district, during the civil war, is the local military of Kuomintang in Jinzhou area. It belongs to the Liaoxi division district, was established in November 1945, and was incorporated by the Communist Party in October 1948. Li Zhuhua was served as the commander. The district consists of several brigades, and the brigades are made up of several squadrons. The squadron leader is responsible for its captain directly; the captain is responsible for the commander. For example: Jinzhou regiment district of the first recruits' brigade, which was composed of nine squadrons. The captain was responsible for the captain Huang Guida, and the captain Huang Guida responsible for the commander Li Zhuhua. Although Jinzhou regiment district only exists more than two years, but this military is more united and stable, so that after the Jinzhou campaign can be successfully incorporated by the Communist Party. The reason why the military are discipline and soldiers are united is that there are with a set of strict and relatively complete reward and punishment system.

Reward and punishment system of soldiers, can be divided into two aspects of soldiers' reward and punishment. Certain means of reward can increase the confidence of the soldier, and encourage soldiers to maintain good character and restrain yourself better. Soldiers who are punished will also be encouraged to follow the rewarded soldiers and give them hope. Different forms of punishment are also constraint and spur to the soldiers. A profound lesson to punished soldiers, keep in mind the military can't violate the regulations and break it. To the soldiers who are not punished to be able to play a warning and or warning role and let them not to make similar mistakes. When combine the two means, it will make the military more orderly, which can receive multiplier effect. Jinzhou regiment district through the combination of rewards and punishments to strengthen management.

\section{District Importance to the Reward and Punishment System of Soldiers}

Liaoxi division district attaches a great importance to the system of reward and punishment system of soldiers and reward and punishment in various ways, which involving in a wide range. Plan as 
whole comprehensively of the entire force management. According to the Liaoxi division and Jinzhou regiment of the district of the telegraphs in 1947, there are 867 telegraphs about reward and punishment system of soldiers, and also have 229 in 1948. Among them, the Liaoxi division district issued 117 articles to the Jinzhou regiment district. And there are 112 articles to answer the Jinzhou regiment district of the applications and reports. Involved specifically in the content, including dismissal, ,promotion, record, notification, penalty and so on.

Jinzhou regiment district is also taken the reward and punishment system of soldiers seriously. The study found that the message reported by Jinzhou regiment district to the Liaoxi division district, which involving the reward telegraphs 425 times, and involving the telegraphs about punishment 386 times. Each report or application content is more detailed. It can be seen that Jinzhou regiment district is responsible for the seriousness and punishment of the district.

\section{Reward System of Soldiers in District}

Reward system of soldiers in district includes promotion, record, reward.

\section{Promotion}

(1) Soldiers can fulfill their duties, work hard, service enthusiastically. On May 3, 1947, Liaoxi division district replied telegraphs to Jinzhou regiment district to permit Zhao Yongxiang and Shi Zhixiangs' promotion application. The reason is that Yue Yuxing and Zhang Dianxue absconded, their jobs are vacant, but considered the expression of Zhao Yongxiang and Shi Zhixiang those are work hard, and with no record of punishment. Then promote them. In February 3, 1948, third squadron captain Wang Junxiu apply for expel the soldier Qian Baoju, and the vacancy added by Li Chunshu who are dedicated and work hard. The first recruits brigade captain Huang Guida also wrote the application, due to the first-rate soldiers Fan Rong who make great efforts in service and to be promoted. Its job is intended to serve the enthusiastic recruits supplied by Yang Linrong. And also the soldier Zhan Jingquan, the captain apply for upgrading because of the enthusiastic service. Eventually these applications are approved by the higher authorities. It can be seen that the work hard and service enthusiasm must be an important condition for the promotion of the soldiers at that time.

(2) Soldiers join the army in a long time and have seniority. In March 9, 1948, the fifth squadron captain Zhou Guangyu had asked the superior, for promoting the second lieutenant Zhou Kunyi to be lieutenant. The reason is that, after thorough examination, Zhou Kunyi joined for a long time, work hard, and seniority in the military, so apply for being promoted the second lieutenant to lieutenant. Eventually, the application was approved two days later. It follows that soldiers enlisted for a long time and seniority, which are also be a condition for the promotion of the soldiers.

(3) Soldiers have the dignified behavior, strong body and their academic is excellent. In November 1, 1947, fourth squadron captain Chu Mingbao, requested the team cooking staff Wu Chunjiang to be raised because of his behavior is dignified, strong body, excellent academic. In January 1948, Jinzhou regiment district cooperatives apply for Sun Yu transferred to the cooperative. The reason is that scattered soldier Wang Xingwu absconded at 1:00 on the 17th of this month, so that there was no one cooking in the cooperation at present. Sun Yuguo characters are dignified and strong, earnestly request the staff transferred to the cooperative services. This application is also approved. Through these two telegraphs can be found that the soldiers can be promoted who are dignified and strong.

\section{Record merit}

(1) Efforts to train, serve for groups. In February 11, 1947, Liaoxi division district issued a written telegraph, Liu Tingxi and Li Yunlong are record merit once because of the efforts to train and service for groups. In the later telegraphs there were also cases that the soldiers were recorded for the same reason. For example: there is an written telegraph with unspecified date, the first squadron captain Guan Falun and lieutenant Li Zhuyi, who training and educating the brigade very hard. The fourth squadron captain Chu Mingbao and lieutenant Liu Jianlei recorded merit twice each person because of the efforts to train and serve for groups. 
(2) Refuse bribes. In October 16, 1947, Liaoxi division district issued a written telegraph, because Zhang Yongliang refused to bribe, it is worth learning, which remembered a great success. Also because of the refusing of bribes are also recognized by Yin Zhongsong, Yang Linsen, Hu Yanben and so on. Liaoxi division district issued by Chen Chengshen written on the 992th text, the investigation of the third squadron Yin Zhongsong, Yang Linsen and the sixth detachment in second squadron captain Hu Yanben. Those three refused to bribe and conscientiously for military service, that be the model for the whole military and ordered the reward. Then decided to record the merit third times each person.

\section{Reward}

The study found that there are many situations that the soldiers were rewarded. Found in the Liaoxi division district issued to the Jinzhou regiment district a commendation of the message is up to 169 articles at present. The reason for the awards is also more complex, and many reasons are the same as those of the soldiers. In general there are several kinds of cases about working hard, service enthusiastic and so on. For example: in May 27, 1947, the command posted the message that the staff Ye Zhaoqin who check the clerk are work hard, and serves enthusiastic. It was send to various counties to complete the inspection service, which was awarded as encouragement. In June 5, 1947, Liaoxi division district command No. 1631 instructions and write to the award to encourage due to the Jinzhou regiment district command captain member Wang Guojun who serves diligence, and effort to enlightenment. In June 5, 1947, Han Zhuo, Chen Yongli are also be commuted due to work hard.

\section{Punishment System of Soldiers in District}

Punishment System of Soldiers in the district includes dismissal, recording, notification and penalties.

\section{Dismissal}

(1) Soldiers service is not enthusiastic, and temperament is uninhibited. In December 18, 1947, the first squadron captain Guan Falun reported to the team sergeant Ma Yingjie. Due to he was fail to keep his post and causing the soldiers fleeing yesterday, so pleaded to expel. It is clear that soldiers' service is not enthusiastic. It will be dismissed because it can not fulfill their duties. The eleventh squadron captain of Jinzhou regiment district has uninhibited temperament. In October 23, 1947, Liaoxi division district powered generation notice, as the eleventh squadron captain outside the name of the troops swagger in the army, self-recruitment, to give the position to cancel the punishment, and to remove the name. If by the name of the military's swagger it will to arrest. In addition, because the soldiers do not keep the discipline, the behavior of the debauchery are dismissed include Zhang Jia and Zheng Yihuan. By investigation of the two, who are without permission even leave without permission, and still do not return to the team in ten days, without disciplined, acts of debauchery, as a cadre soldiers should not be so, and leave temporary outside the military for removing supervision. Off the act so as to affect the division of the whole district, if not remove their name from the rolls, the future was embarrassing. Remove the name. Through the above message can be found, if the soldiers in the military serves is not enthusiastic and the behavior is full of dissolute will be dismissed.

(2) The soldiers do not be back after short leaving or out of the limited date. Liaoxi division district file expressly stipulates that the soldiers out of limited time should give punishment, the severe patience to be dismissed. In October 30, 1947, Commander Li Zhuhua issued the rule, soldiers have too much absence which is not normal. The competent organization will leave the military can not return to till November 1 reported that the expulsion of the program is to be notified. It can be seen that whether it is the Liaoxi division district or Jinzhou regiment district, the soldiers who can not return implement strict management.

(3) The soldiers' physical examination is failed. The first recruits brigade captain Huang Guida reported that the third squadron military cook Sun Han who because of the physical examination was failed to expel. And raised a good physical quality of a soldier, and then fill its vacancies. In February 5, 1948, the first recruits brigade captain Huang Guida asked the higher authorities, 
because some of the soldiers do service unbearable and be dismissed due to serious illness. It can be seen, the military are strict to the physical quality of soldiers.

\section{Record demerit}

The research found that, it is the common means that recorded punishment to the soldiers in the Liaoxi division district. This involving many people, some have been recorded once, and some have been recorded many times. Liaoxi division district has also issued a provision of text, which was recorded personnel pay 20 percent penalty. If you can not comply with the military management system, which from the main officer to all levels of soldiers, has been recorded possible. In November 17, 1947, fourth squadron Chu Mingbao found that the team soldier Meng Hui violate the fate of the district requirements. So give record punishment to him. In November 23, 1947 Liaoxi division district telegraph that third squadron captain Wang Junxiu and fourth squadron captain Chu Mingbao recorded twice due to management neglect.

\section{Notification}

In March 9, 1948, Jinzhou regiment district of the first recruits brigade fifth squadron captain Zhou Guangyu had asked the commander to give soldier Xia Wenbin the punishment. The reason is that the Xia Wenbin as the regimental confinement room service squad leader, due to leave the post so that the scattered soldier Wang Jianguo was fled, so give Xia Wenbin the notice of punishment. This application was ordered by Li Zhuhua and gave him the notice. It can be seen that Jinzhou regiment district for the soldiers will be given a notice of punishment due to absent.

\section{Penalty}

In order to have a strict leaving system for Liaoxi division district, in November 13, 1947, the telegraph of the daily military leaving quantity should not exceed ten. Ill soldiers can rest in the resting room, and the soldiers who have the official business should must keep the note in time, and keep the leave note, the military need to call the name regularly, the whole soldiers need to reach, dress uniform neatly. Prohibition of temporary leaving, such as the absence of soldiers for no reason should pay penalty. deducting full monthly forage, and all levels of the main officials have the joint responsibility.

\section{Comment Analysis}

Effective soldiers reward and punishment system, can boost morale, improve the cohesion and combat effectiveness. Invalid or unfair reward and punishment, resulting in low morale, is not conducive to the unity and stability of the troops. Through the study found that the reward and punishment system of soldiers in Jinzhou regiment is more comprehensive and democratic, but there are some shortcomings and deficiencies, the reward and punishment means are too simple, and the limits of reward and punishment are unclear.

\section{Advantage}

(1) More democratic. Liaoxi division district has issue the telegraph requirments of the soldiers who were punished can be filed. According to statistics, in Jinzhou regiment district, soldiers who was punished had 243 times to complain, due to unreasonable punishment, which has repeatedly cancel the treatment. As you see, the reward and punishment system of soldiers in Jinzhou regiment district is more democratic.

(2) Wide covering range. The reward and punishment system in the district involves many aspects of the soldiers. It is including leaving system, physical quality requirements, clothing, work attitude, character, temperament, age and so on. Reward and punishment system involves each soldier, not only for the individual soldier, but also for the collective rewards and punishments, but the mainly based on the individual. For example: June 21, 1947, the telegraph of headquarters, because arrangement of Jinzhou regiment district for the soldiers, have successfully welcomed the army, and in the health inspection was the most neat clothes and socks, soldiers physically strong, well-trained, which shows the good management of the district, therefore give the special order award to encourage. 


\section{Disadvantages}

(1) The means of reward and punishment are too simple. The reward mean of the soldiers in Jinzhou regiment, mainly divided into promotion, record, reward and other three kinds, the punishment mean is mainly dismissal, record, notification, penalty and other four kinds. The means of reward and punishment are too simple, the army should be based on different circumstances to master the rewards and punishments of soldiers, should not be limited in these ways. Such reward and punishment means will cause unfair treatment to the soldiers.

(2) The limit of rewards and punishments is unclear. The rewards and punishments of soldiers in Jinzhou regiment have more overlap. As for hard work and enthusiastic service, such the reason for some soldiers may be promoted, but some soldiers are only awarded. As for the service is not enthusiastic, some soldiers may be dismissed, but some soldiers may only be notified. This situation will cause a lot of soldiers dissatisfied about rewards and punishments, complaints, and gradually make the rewards and punishments system lose authority. Some reasons of rewards and punishments are too vague, too simple, arbitrary, and sometimes difficult to convince the public. Although the Liaoxi division district's reward and punishment system is more stringent, but also specifically issue the telegraph requirements must comply, but in the real practice, sometimes still in vain, can not well implement.

\section{Conclusion}

Reward and punishment system of soldiers, is the implementation of incentives and disciplinary procedures in the army, is an important mean of maintaining discipline, is part of the military system. Effective reward and punishment system of soldiers help to inspire the morale of the army, and make the military discipline strict. The reward and punishment system of soldiers Jinzhou regiment, although there are many shortcomings, but in general it is still relatively strict and effective, so that Jinzhou regiment before the battle has been in relatively stable state, and is conducive to the successful collection of Communist Party subsequently.

\section{References}

[1] Jinzhou Archives Bureau, "The puppet army archives 232: Jinzhou regiment district about personnel commendation," 1945.

[2] Jinzhou Archives Bureau, "The puppet army archives 268: Supplementary form of Jinzhou regiment District Command," 1946.

[3] Jinzhou Archives Bureau, "The puppet army archives 271: Jinzhou regiment district headquarters on the recruitment of soldiers table," 1947.

[4] Jinzhou Archives Bureau, "The puppet army archives 294: Jinzhou regiment district first recruit battalion about the expulsion of soldiers and the roster of sergeants," 1947.

[5] Jinzhou Archives Bureau, "The puppet army archives 340: Jinzhou regiment district first recruit battalion about the personnel reward merit order," 1948.

[6] Jinzhou Archives Bureau, "The puppet army archives 352: Jinzhou regiment district command, the first recruit battalion of the first squadron of soldiers on the rise, fill and dismissal," 1948.

[7] S. J. Xu, "Research on incentive mechanism of army management," Master's Degree of Information Engineering University, 2005.

[8] Z. Li, "Research on the incentive mechanism of NCO," Master's Degree of South China University of Technology, 2015.

[9] M. Kong, "On China's military reward and punishment system in the late Qing Dynasty and the early republic of China," Master's Degree of Henan University, 2006.

[10] M. Li, "Study of College Graduates Psychological Health Educating Model Construction," Master's Degree of University of Electronic Science and Technology, 2013.

[11] G. J. Wang, H. P. Cheng, "Analysis of Zhang Zhizhong's military thought," Jilin Normal University Journal(Humanities \& Social Science Edition), vol. 35, no. 4, pp. 83-86, 2007. 